\title{
O TEMA ÁGUA E SUA INSERÇÃO NOS LIVROS DIDÁTICOS DE CIÊNCIAS DO ENSINO FUNDAMENTAL
}

\author{
Natália Teixeira Ananias Freitas, Fátima Aparecida Dias Gomes Marin \\ Universidade Estadual Paulista - FCT/UNESP, Departamento de Educação, Programa de Pós-Graduação em Educação, \\ Presidente Prudente, SP. E-mail: nathyteixeira@hotmail.com
}

\section{RESUMO}

Este artigo apresenta parte dos dados obtidos na investigação "Educação ambiental e água: concepções e práticas educativas em escolas municipais", vinculada a FCT/UNESP. Investigou-se como o tema água comparece nos Projetos Especiais das Escolas; nos planos de ensino; nos livros didáticos de Ciências e de Geografia adotados pelo município e como é abordado pelos docentes, a partir das suas concepções teórico-metodológicas. Por meio de um recorte, apresentamos as discussões que são relacionadas aos livros didáticos de Ciências. A pesquisa se caracteriza pela abordagem qualitativa e estudo de caso, conforme protocolo do CEP 86/2010. A investigação permitiu concluir que o tema água é tratado com superficialidade e de maneira fragmentada nos Livros Didáticos de Ciências, necessitando que alunos e professor utilizem outros materiais complementares para a abordagem do tema em sala de aula.

Palavras-chave: Água; Livro Didático de Ciências; Educação Ambiental; Ensino Fundamental.

\section{THE WATER AND INSERT YOUR TOPIC IN SCIENCE TEXTBOOKS OF ELEMENTARY EDUCATION}

\begin{abstract}
This article presents part of the data obtained in the investigation "Environmental and Water Education: educational conceptions and practices in municipal schools", linked to FCT / UNESP. We investigated how the theme water attending the Special Projects of Schools; in the syllabus; in textbooks of Sciences and Geography adopted by the municipality and how is approached by teachers, from its theoretical and methodological conceptions. Through a cut, we present the discussions that are related to Science textbooks. The research is characterized by qualitative approach and case study as of 86/2010 CEP protocol. The investigation has concluded that the water theme is treated superficially and fragmented in Textbook of Sciences manner, requiring that students and teachers use other supplementary materials to approach the subject in the classroom.
\end{abstract}

Keywords: Water; Sciences Textbooks; Environmental Education; Basic Education

\section{INTRODUÇÃO}

Este trabalho é parte integrante da pesquisa de Mestrado intitulada: "Educação Ambiental e água: concepções e práticas educativas em escolas municipais", vinculada ao Programa de Pós-Graduação em Educação, da FCT/UNESP, Presidente Prudente, SP.

A água é considerada como um dos recursos naturais mais importantes para a manutenção e continuidade da vida no planeta. Contudo, sua distribuição entre os países não acontece de forma igualitária, conforme apontam os estudos de Tundisi (2003) e Rebouças (2003), o que leva a incidência de uma crise hídrica em vários países.

O tema água é um assunto constantemente em pauta no cotidiano dos cidadãos, abordado por diversas mídias, segmentos sociais e presente em documentos curriculares, legislações, em livros didáticos e objeto de propostas pedagógicas. Estudiosos advertem que a água potável está sendo deteriorada pela ação antrópica, o que tem revelado a urgência de ações para recuperar, conservar e preservar os recursos hídricos.

Guimarães (2006 apud SILVA, 2009) afirma que é necessária uma reflexão sobre os 
problemas ambientais presentes na sociedade. Para o autor, somente o conhecimento da existência desses problemas não proporciona modificações no meio ambiente.

O papel do professor é de suma importância ao contribuir para a formação dos alunos com práticas educativas voltadas à compreensão da realidade local e global e o fomento de hábitos e atitudes no que diz respeito ao uso racional da água.

Atenta à relevância dessa formação profissional, o objetivo geral da pesquisa consistiu em investigar como o tema água é abordado nas escolas municipais e quais as concepções e práticas docentes. Os objetivos específicos da pesquisa foram:

- Discutir o tema água e a sua relevância para a formação do aluno no sentido de compreender e intervir na realidade;

- Avaliar como o tema água comparece nos Projetos Especiais dos Planos Diretores das escolas, nos planos de ensino, livros didáticos de Geografia e de Ciências, nos materiais enviados aos professores da Rede Municipal de Ensino para o trabalho com a Educação Ambiental, e em outros materiais indicados pelos docentes.

- Considerar e avaliar as concepções, saberes e práticas educativas dos professores pertencentes às escolas pesquisadas sobre a Educação Ambiental e água.

- Apresentar e problematizar os resultados, as experiências bem sucedidas, as fragilidades e as lacunas dos trabalhos desenvolvidos na rede municipal de ensino.

Para este artigo, apresentamos as discussões referentes aos Livros Didáticos de Ciências, considerando um recorte a partir dos dados obtidos e analisados na pesquisa em questão.

\section{METODOLOGIA}

A pesquisa se caracteriza pela abordagem qualitativa e pelo estudo de caso. O seu desenvolvimento contemplou a revisão bibliográfica, escolha das escolas, coleta, análise e sistematização dos dados.

A abordagem qualitativa exprime e considera a qualidade dos dados a serem coletados. Os estudos de Bauer e Gaskell (2002, p.23), avaliam que esse tipo de método "[...] evita números, lida com interpretações das realidades sociais.".

A pesquisa constituiu-se em um estudo de caso. Para Severino (2007, p.121), o estudo de caso é uma "[...] pesquisa que se concentra no estudo de um caso particular, considerado representativo de um conjunto de casos análogos, por ele significativamente representativo". Desse modo, esta pesquisa possuiu como caso investigar a Educação Ambiental e o tema água na Rede Municipal de Ensino de uma cidade do interior do estado de São Paulo, especificamente na prática docente de quatro professores.

Considerando os dados apresentados neste artigo, as análises referentes aos Livros Didáticos de Ciências e o tema água possuíram como base o referencial teórico de Rebouças (2002), Tundisi (2003), Carvalho (2008), Bortolozzi (1997), Dias (2000), entre outros, além de contemplar uma estratégia documental, já que os livros didáticos nesta pesquisa apresentam-se como fonte de aprendizado para alunos e importante âncora para os docentes investigados a respeito do tema água.

$O$ desenvolvimento da pesquisa recebeu respaldo do Comitê de Ética em Pesquisa da FCT/UNESP, conforme o protocolo 86/2010, garantindo a validade e fidedignidade dos dados obtidos e analisados.

\section{DISCUSSÃO}

\section{O tema água e os Livros Didáticos}

A água é considerada um elemento essencial para a vida de um indivíduo. A sua presença é fundamental no corpo humano e nas diversas situações cotidianas que requerem o uso desse recurso.

A respeito da quantidade de água na superfície terrestre, Tundisi (2003) alerta que a grande questão recai sobre a escassez de água no mundo.

Nas palavras de Tundisi $(2003$, p.5)

O ciclo hidrológico é o princípio unificador fundamental de tudo o que se refere à água no planeta. O ciclo é o modelo pela qual se representam a interdependência e o movimento contínuo de água nas fases sólidas, líquida e gasosa. Toda água do planeta está em contínuo 
movimento cíclico entre as reservas sólida, líquida e gasosa. Evidentemente, a fase de maior interesse é a líquida, o que é fundamental para o uso e para satisfazer as necessidades do homem e de todos os outros organismos, animais e vegetais.

O Brasil é considerado um dos ambientes com maior disponibilidade de água doce no mundo, porém, apresenta uma concentração desigual desse recurso para atender a população, conforme dados do Instituto Brasileiro de Geografia e Estatística (IBGE) no último censo demográfico realizado em 2010.

De acordo com Barros (2010) 89\% do volume total da água doce do Brasil que está na Região Norte e Centro-Oeste é colocada à disposição de $14,5 \%$ da população total, enquanto que para as regiões Nordeste, Sudeste e Sul, onde estão distribuídas $85,5 \%$ da população do país, há disponível apenas $11 \%$ de água. Semelhante ao que ocorre em alguns pontos do mundo, esses dados indicam uma desigual distribuição de água. Nesse sentido, o Brasil dispõe de áreas ricas de água doce com poucos habitantes e em contrapartida, localidades populosas que sofrem com a carência dos recursos hídricos.

Concordando com Tundisi (2003), vivemos hoje uma crise hídrica, ou seja, conflitos, políticas e crises ambientais que possuem como mote a água, devido a fatores diversos, tais como: crescimento populacional que afeta as áreas de mananciais hídricos; processo de urbanização, transformando locais de preservação ambiental em cidades e empreendimentos comerciais; padrões de vida e de consumo desenfreados, que não valorizam os recursos naturais; poluição; falta de planejamento do poder público e de sensibilização ambiental; ponto este que afeta diretamente a Educação. Indivíduos mais esclarecidos sobre os fatos que norteiam o seu cotidiano podem contribuir com ações no sentido de recuperar, conservar e preservar os recursos hídricos.

Portanto, defendemos uma Educação Ambiental, que não se restrinja a apontamentos ou denúncias a respeito de problemas ambientais, mas que estabeleça princípios educativos que contribuam para a aquisição de conhecimentos, habilidades e atitudes a respeito dos recursos naturais.

Como aporte para as discussões sobre água no contexto de sala de aula, destacamos como fonte de informação os livros didáticos. De acordo com Gatti Junior (2004), os livros didáticos são "objetos da cultura escolar". O livro didático se apresenta principalmente para o ensino público e gratuito, como uma forma de "garantia" educacional para todos aqueles que se utilizam desse material.

Ao revisitarmos o contexto histórico da Educação no Brasil, percebe-se que a implantação e melhoria das atividades educativas nas escolas públicas possuíram como base a presença do Livro Didático.

Em meados da década de 1930, onde encontramos os manuais didáticos, mais precisamente no ano de 1938, são criadas as primeiras políticas sobre o Livro Didático, com apoio do Instituto Nacional do Livro (INL), para um aumento de produção dos livros e legitimação desse material por todo o país, instituindo assim, a Comissão Nacional do Livro Didático.

Na década de 1940, por meio do DecretoLei no 8460, de 26 de Dezembro de 1945, o Governo consolida uma legislação sobre as formas de produção do Livro Didático, a sua utilização e importação, deixando a cargo dos docentes a escolha dos livros que serão consumidos nas escolas.

Por volta dos anos de 1960, o Ministério da Educação e Cultura (MEC), juntamente com uma agência norte-americana para o desenvolvimento internacional (USAID), estabelecem convênios que direcionam verbas para a distribuição gratuita de 51 milhões de livros, em um período de três anos, continuando também depois de algum tempo.

Nos anos de 1970, encerra-se o convênio MEC/USAID, e o Estado cria o "Fundo do Livro Didático", um sistema financeiro que efetivasse verbas para a compra e envio dos exemplares às escolas. Além desse ponto, o Instituto Nacional do Livro (INL) dá início a um programa para os Livros Didáticos do Ensino Fundamental (PLIDEF), coordenado pelo próprio país. Em 1976, extingue-se $0 \mathrm{INL}$, criando-se $\mathrm{O}$ FENAME (Fundação Nacional do Material Escolar), que responde nesse momento como executor do Programa do Livro Didático em escolas públicas 
somente, devido a poucos recursos do Fundo Nacional de Desenvolvimento da Educação (FNDE).

Adentrando nos anos de 1980, a FENAME é substituída pela FAE (Fundo de Assistência ao Estudante), que incorpora o PLIDEF. Com a instituição do decreto no 91.542, de 19 de agosto de 1985, algumas mudanças em toda a rede existente sobre os Livros Didáticos acontecem, como, por exemplo, a reutilização dos livros por mais estudantes, implantação de banco de dados de Livro Didático, controle total do Governo Federal sem participação dos Estados, entre outros aspectos.

Nos anos de 1990, por limitações de orçamento governamental, os Livros Didáticos são restritos somente até a 4a série do Ensino Fundamental (atualmente o 5o ano.). Em 1995, com a volta de mais investimentos para a Educação, a distribuição dos Livros Didáticos ao Ensino Fundamental volta a acontecer normalmente.

Já em 1996, forma-se uma comissão que começa a avaliar os Livros Didáticos, para melhorar a escolha dos exemplares pelos professores, fato este que ocorre até os dias de hoje. Destacamos nesta década também uma comercialização dos Livros Didáticos de História e Geografia no ano de 1997 pelo Governo Federal, acoplados aos já existentes, ou seja, Língua Portuguesa, Matemática e Ciências.

Após o ano 2000, são desenvolvidos exemplares didáticos para alunos portadores de necessidades especiais, incluindo também a distribuição de dicionários de Língua Portuguesa, Inglesa e Espanhola, Atlas Geográfico, entre outros materiais, contribuindo para uma educação mais acessível aos conteúdos escolares, e que colaboram significativamente com as atividades propostas pelos Livros Didáticos.

Considerando alguns aspectos do histórico dos Livros Didáticos, percebe-se a importância desses materiais no trabalho docente. Não obstante, o seu uso requer cuidados. É imprescindível oferecer aos alunos situações que lhes permitam pesquisar, contextualizar os conhecimentos e acrescentar outros materiais para enriquecer as atividades propostas nos livros, tais como filmes, revistas, jornais, pesquisas na internet, imagens, histórias em quadrinhos, livros de literatura infantil, entre outros materiais. Aos professores, cabe à tarefa de aprofundar os saberes, evitar a fragmentação dos conhecimentos, complementar as lacunas e superar as fragilidades desses materiais.

A partir da discussão teórica realizada a respeito do tema água e o papel dos Livros Didáticos no contexto do Ensino Fundamental, a seguir, apresentamos as análises correspondentes aos Livros Didáticos de Ciências.

\section{Analisando os livros didáticos de Ciências: 0 tema água em questão}

As coleções de livros didáticos que apresentam o tema água em nossa pesquisa são referentes à área de Ciências e Geografia. Todas as escolas investigadas adotam os mesmos livros didáticos: Coleção "Aprendendo Sempre" Ciências e Coleção "Asas para voar - Geografia". Nesta ocasião, apresentamos as análises da coleção referente à área de Ciências.

Os livros fazem parte do Programa Nacional do Livro Didático (PNLD 2010-2012), administrado pelo Governo Federal por meio do MEC. Os alunos e docentes da Rede Municipal de Ensino têm acesso a esses materiais, o que em tese colabora para qualificar a abordagem do tema água e não restringir a sua discussão somente ao "Dia da água", por exemplo.

De acordo com o Guia Nacional do Livro Didático (PNLD 2010-2012) para a área de Ciências, a Coleção "Aprendendo Sempre" - 2음 ao 5 o ano do Ensino Fundamental - Ed. Ática, pode ser descrita da seguinte forma:

A coleção é constituída por quatro livros que seguem o mesmo padrão de distribuição dos conteúdos. Cada um é constituído por 15 módulos de estudo, distribuídos em quatro unidades. A estrutura conceitual do conhecimento trabalhado na coleção baseia-se em quatro áreas: Ciências da Vida, Ciências da Terra, Ciências da Técnica (ou Tecnologia) e Primeiras noções de Química e Física. [...] (BRASIL,2009,p. 27)

Na coleção "Aprendendo Sempre" Ciências - o tema água organizado em unidades específicas comparece somente no volume do $4 \underline{0}$ ano. Os conteúdos para este volume são divididos da seguinte forma: 
Unidade I - Ambiente e seres vivos: Explorar o Pantanal; Cadeias alimentares; Espécies em desaparecimento;

Reprodução e desenvolvimento. Unidade II - Água, solo e ser humano: A água no dia-a-dia; Tratando a água; $O$ solo e sua ocupação; Solo e vegetação. Unidade III - Da natureza para o lixo; Recursos naturais; O sal e a água; Os metais; Lixo e reciclagem. Unidade IV - Invenções, eletricidade e consumo: Máquinas e energia; Instalações elétricas; Consumo de energia elétrica. (BRASIL, 2009, p.28)

Entre as atividades solicitadas nos diferentes módulos contemplam: análise de imagens, trabalhos em grupo, realização de experimentos, pesquisas, leitura de artigos de jornal, questionário.

Uma das questões direcionadas aos estudantes por intermédio do livro é: "Será que no futuro teremos água boa e em quantidade suficiente para utilizar todos os dias?" (NIGRO e CAMPOS, 2010,p.54). Esta questão é seguida de um texto intitulado: "Haverá água quando a gente ficar velho?" adaptado do Jornal "Folha de São Paulo, caderno Folhinha, 14 fev.1998" sobre o desperdício. Após esta matéria, são apresentadas várias ilustrações que demonstram a poluição e o desperdício da água no cotidiano, bem como atitudes de uso racional da água e descarte do lixo. Ao final desta atividade, é solicitado que o aluno "[...] faça o desenho de uma situação em que você esteja utilizando água sem desperdiçá-la nem poluí-la. Depois, cole essa folha no mural da classe". (NIGRO e CAMPOS, 2010, p.55)

Consta também, uma história em quadrinhos para que o aluno reflita sobre como temos usado a água e é solicitado que o aluno "pesquise notícias nos jornais e troque ideias com seus colegas sobre como temos utilizado a água. Depois, elabore uma história em quadrinhos sobre o seguinte tema: Como temos cuidado da água?" (NIGRO e CAMPOS, 2010, p.56). Num tópico intitulado "Hora da Leitura" consta um texto denominado "Economizar água".

Verifica-se que os autores tiveram uma preocupação com os conteúdos atitudinais, neste caso, estimular hábitos, atitudes e comportamentos voltados para o uso racional da água. Esta iniciativa está de acordo com uma das indicações do artigo 10 da Política Nacional de Educação Ambiental, Lei no 9795, de 27 de abril de 1999 que estabelece a Educação Ambiental como:

[...] os processos por meio dos quais o indivíduo e a coletividade constroem valores sociais, conhecimentos, habilidades, atitudes e competências voltadas para a conservação do meio ambiente, bem de uso comum do povo, essencial à sadia qualidade de vida e sua sustentabilidade. (BRASIL, 1999)

Apesar da relevância de se trabalhar com os conteúdos atitudinais, constatamos uma fragilidade na abordagem dos conteúdos conceituais. Por mais que os autores motivem a realização de discussões sobre o uso da água, o futuro da água, o cuidado para evitar o desperdício e a poluição da água no cotidiano, é primordial o aprofundamento do referencial teórico. Em algumas situações é atribuída ao aluno a tarefa de pesquisar em "notícias de jornais" sobre a utilização da água (NIGRO e CAMPOS, 2010, p. 56). A realização de pesquisa pelo aluno é uma atividade importante, conforme aponta Libâneo (1994), contudo é essencial ter alguns cuidados, por exemplo: avaliar a qualidade dos materiais de pesquisa, os textos produzidos pela mídia. Por outro lado, espera-se que os livros didáticos apresentem conteúdos conceituais e que os professores tenham domínio da matéria para que os alunos tenham acesso aos conhecimentos científicos. A intenção é que as interpretações da realidade não fiquem restritas ao senso comum.

No módulo 5 do Livro didático de Ciências, são apresentadas discussões sobre as doenças que a população enfrenta em conseqüência da contaminação da água, como a Diarréia e a Cólera. Discute-se também, a proliferação do mosquito da Dengue, em "água 
limpa e parada". Estes temas são abordados tendo como referência adaptações de textos jornalísticos.

O módulo seguinte concentra suas atividades no tratamento da água, com uma pergunta inicial: "Será que essa água é boa para beber?", mostrando uma continuidade nas discussões apontadas pelo livro. Neste módulo, por apresentar como âncora o tratamento da água, algumas atividades práticas são sugeridas aos alunos, como a construção de uma maquete do sistema de água de uma cidade, maneiras de separar misturas - decantação e filtração - e simulação de uma rede de distribuição de água.

$O$ aluno é convidado a realizar atividades práticas, sejam elas individuais ou em grupo, porém não se percebe um aprofundamento teórico para subsidiar estas ações, exigindo do professor um trabalho complementar.

O módulo 10 (NIGRO e CAMPOS, 2010, p.104), que tem como título: "O sal e a água" contempla uma discussão sobre a obtenção do sal e a presença dele no mar. São apresentadas fotos do trabalho em uma salina e sugerida pesquisa "[...] sobre salinas e exploração de sal no Brasil" (NIGRO e CAMPOS, 2010, p.106-107)

Algumas cidades, como por exemplo, Barcelona (Espanha), Riad (Arábia Saudita), Perth (Austrália Ocidental) e Nicósia (Turquia) utilizam para o abastecimento a água proveniente de processo de dessalinização. Ao tratar do sal e a água seria enriquecedor que o livro didático abordasse também este assunto.

Através do subtítulo "Os caminhos da água" (NIGRO e CAMPOS, 2010, p. 110), o livro instiga o aluno a discutir com seus colegas sobre o que acontece com a água que evapora. São apresentadas várias questões: "O que vocês acham que existe nas nuvens?" "De que vocês acham que as nuvens são formadas?" "De onde vocês acham que vem a água das chuvas?" Estes questionamentos são seguidos de um pequeno trecho adaptado do livro "Por quê? - Clima, Editora Ática".

É solicitado ao aluno a organização um quadro para comparar seus conhecimentos prévios aos identificados no texto a respeito das questões. São apresentadas ilustrações a respeito do "Ciclo da água" na natureza, porém as informações não são aprofundadas.

A respeito disso, Tundisi (2003, p.5) afirma que o ciclo hidrológico é um dos princípios mais importantes quando se refere a disponibilidade de água potável no planeta. Por meio desse ciclo que a água realiza sua movimentação e renovação na terra. Dessa forma, é importante que esse tema seja abordado com profundidade, em adequação a condições cognitivas dos alunos e direcionamento por parte do professor, para que o aluno compreenda a presença da água no seu contexto vivido e a importância da água potável para manutenção da vida humana.

Como conclusão deste módulo, apresenta-se uma discussão sobre a água sólida e o conceito de solidificação, com fotos a respeito do momento em que a água está no estado líquido e passa para o estado sólido, a exemplo do que é feito ao colocar uma forma de gelo no congelador de uma geladeira. Percebe-se que o livro não faz uma ligação com o tema abordado na página anterior, ou seja, o ciclo hidrológico e suas fases.

Diante da descrição dos conteúdos e atividades presentes na coleção "Aprendendo Sempre: Ciências" a água é entendida como um elemento essencial para o dia a dia do ser humano e que precisa ser utilizada de maneira racional para que não venha a faltar. Os conceitos priorizados nos capítulos dizem respeito ao uso da água nas atividades cotidianas, situações de economia e abastecimento de água, as doenças transmitidas pela água, o sal e a água, o ciclo da água e os seus estados físicos.

\section{RESULTADOS}

O Livro Didático de Ciências apresenta uma preocupação com os conteúdos atitudinais, especificamente no que tange ao estímulo de hábitos, atitudes e comportamentos voltados para o uso racional da água. Todavia, as atividades em grupo propostas para a vivência do tema água no contexto de sala de água são somente apontadas no livro, não recebendo embasamento teórico para sua realização. Constatamos uma fragilidade na abordagem dos conteúdos conceituais.

\section{CONCLUSÃO}

Os Livros Didáticos são considerados importantes materiais para o ensino do tema água no contexto do Ensino Fundamental. Contudo, é recomendável que os livros sejam utilizados com o apoio de outros materiais, como por exemplo, filmes, notícias de jornais e revistas, textos, poesias, ilustrações, jogos, o que colaboraria ainda mais com o trabalho do 
professor e a sensibilização do tema água na vida dos alunos.

A coleção analisada procura contemplar várias questões a respeito da água. Como aspecto positivo, destacamos as atividades que colaboram para que o aluno adquira conteúdos atitudinais a respeito do tema, porém, são observadas algumas lacunas correspondentes aos conteúdos conceituais, necessitando da intervenção do professor para que o aluno possa compreender e intervir na realidade.

Cabe a cada um de nós assumir o seu papel frente às questões ambientais e principalmente a água, elemento essencial para a vida. Indivíduos mais conscientes e atentos às questões ambientais são capazes de contribuir no sentido de conservar, recuperar e preservar os recursos hídricos.

\section{AGRADECIMENTOS}

Agradecemos a Coordenadoria de Aperfeiçoamento de Pessoal de Ensino Superior (CAPES) pela concessão de bolsa de estudos para realização desta pesquisa e também a Secretaria Municipal de Educação de Presidente Prudente (SEDUC) pela autorização em realizar a pesquisa nas Escolas Municipais de Ensino Fundamental de Presidente Prudente.

\section{REFERÊNCIAS}

BAUER, M.W,; GASKELL, G. Pesquisa qualitativa com texto, imagem e som: um manual prático. Petrópolis: Vozes, 2002.

BRASIL. Lei no 9795 de 27 de abril de 1999. Dispõe sobre a educação ambiental, institui a Política Nacional de Educação Ambiental e dá outras providências. Brasília, 27 de abril de 1999. Disponível em:< http://www.planalto.gov.br/ccivil 03/LEIS/L9795 .htm.> Acesso em 11/08/10

BRASIL, Ministério da Educação. Guia de Livros Didáticos - PNLD 2010- Ciências. Brasília: $\mathrm{MEC} / \mathrm{SEB}, \quad 2009,89$ p. Disponível em $<$ ftp://ftp.fnde.gov.br/web/livro didatico/guia $p$ nld 2010/ciencias.pdf> Acesso em Março de 2012.

BORTOLOZZI, Arlêude. Educação Ambiental e o Ensino de Geografia: bacias dos rios Piracicaba, Capivari e Jundiaí. 268f. Tese (Doutorado em Educação) - Faculdade de Educação,Universidade Estadual de Campinas. Campinas, 1997.

CARVALHO, V. S. de. A educação ambiental nos PCNs: o meio ambiente como tema transversal. In: MACHADO, C.et.al. Educação ambiental consciente. Rio de Janeiro: WAK Editora, 2008. p.83-102.

DIAS, G.F. Educação Ambiental: princípios e práticas. São Paulo: Editora Gaia, 2000,551p.

GATTI JUNIOR, D. A escrita escolar da História: Livro didático e ensino no Brasil(1970-1990). Bauru, Edusc, 2004,250p.

LIBÂNEO, J.C. Didática. São Paulo: Cortez, 1994, 262 p. (Coleção Magistério - Série Formação do Professor)

NIGRO, R.G; CAMPOS, M.C. da C. Ciências. São Paulo: Ática, 2010, 224p. (Coleção Aprendendo Sempre - 40 ano)

REBOUÇAS, A.C. Água no Brasil: Abundância, desperdício e escassez. Revista Bahia Análise e Dados, número especial, p.341-345, 2003. Disponível em HTTP://www.bvsde.paho.org/busacd/cd17/abun dabras.pdf. Acesso em Jan.2011.

SEVERINO, A.J. Metodologia do Trabalho Científico. São Paulo: Cortez Editora, 2007,304p. SILVA, Aline Pereira da. Educação ambiental em resíduos sólidos nas unidades escolares municipais de Presidente Prudente-SP. 2009. 207p. Dissertação (Mestrado em Geografia) Faculdade de Ciências e Tecnologia, Universidade Estadual Paulista, Presidente Prudente-SP.

TUNDISI, José Galizia. Água no século XXI: enfrentando a escassez. São Carlos: RIMA, 2.ed.,2003.

Recebido para publicação em 02/09/2014

Revisado em 15/03/2016

Aceito em 28/11/2016 